\title{
O engajamento e o ensaio: o político e a política na Primeira República Brasileira
}

Clayton José Ferreira*

\begin{abstract}
RESUMO
Serão abordadas neste artigo algumas das possibilidades no interior dos ensaios $O$ colono preto como fator da civilização brasileira (1918) de Manuel Querino e O Brasil na História: deturpação das tradições, degradação política (1930) de Manoel Bomfim. As hipóteses são as seguintes: 1) a partir das perspectivas de Pierre Rosanvallon, é apontado que, mesmo não atuando na administração estatal (a política), ambos os autores estavam intensamente engajados em refletir e debater acerca das possibilidades de ação na sua cotidianidade ("o político"); 2) Para os dois autores, o conhecimento histórico era central para a produção deste saber comprometido com as questões de sua contemporaneidade.
\end{abstract}

Palavras-chave: História das ideias. Manuel Querino. Manoel Bomfim.

\section{The commitment and the essay: the political and the politic in the First Brazilian Republic}

\begin{abstract}
Some of the possibilities within the following essays will be approached in this article: $O$ colono preto como fator da civilização brasileira (1918) by Manuel Querino and O Brasil na História: deturpação das tradições, degradação política (1930) by Manoel Bomfim. The hypotheses are as follows: 1) from the perspectives of Pierre Rosanvallon, it is pointed out that, even though not acting in the state administration (the politics), both authors were intensely engaged in reflecting and debating about the possibilities of action in their daily lives (the political); 2) For both authors, historical knowledge was central to the production of this committed knowledge to the issues of their contemporaneity.
\end{abstract}

Keywords: History of ideas. Manuel Querino. Manoel Bomfim.

Artigo recebido em 3 out. 2018

Artigo aprovado em 2 abr. 2019

\footnotetext{
* Doutorando pelo programa de pós-graduação em história da Universidade Federal de Ouro Preto (UFOP) onde desenvolve o projeto de tese "Dimensões ético-políticas nas estratégias pragmáticas e estéticas em ensaios da primeira república". O presente trabalho foi realizado com apoio da Coordenação de Aperfeiçoamento de Pessoal de Nível Superior - Brasil (CAPES) - Código de Financiamento 001, sob orientação do Prof. Dr. Marcelo de Mello Rangel. Email: claytonjf15@hotmail.com.
} 


\section{Atividade intelectual, ética e política}

Neste texto, pretendo apontar algumas possibilidades acerca da atividade intelectual no início do século XX brasileiro. Abordarei o que acredito ser uma aproximação mais intensa do "político" nos textos destes dois autores, onde a reflexão a respeito das perspectivas de ação no presente se preocupa profundamente em se constituir apoiado na representação e narrativa das experiências passadas. Inicialmente, tematizaremos "o político" nos ensaios O colono preto como fator da civilização brasileira (1918) do historiador e militante negro Manuel Querino (1851-1923) e O Brasil na História: deturpação das tradições, degradação política (1930) de Manoel Bomfim (1868-1932). Em seguida, tematizaremos a escrita da história nestes textos acerca da perspectiva do "político".

As questões aqui abordadas buscam se orientar a partir da crítica a história intelectual ou das ideias a qual, a partir de então "[...] se abre para as complexas dimensões do social, do político e do econômico (SOARES, 2011, p. 87). Deste modo, "Caberia ao historiador, nesse sentido, trabalhar a descrição dos fatos da mentalidade, buscando as estruturas de pensamento de cada época, comandadas pelas evoluções socioeconômicas que organizam as construções intelectuais" (Soares, 2011, p. 89).

Tal renovação apoiava-se na crítica à noção de conceitos que nascem de inteligências desencarnadas, fora de seu tempo e de seu espaço. O pensamento era antes visto como não tendo limites, separado das formas de vida social que permitem sua produção e sujeito, unicamente, à influência das grandes ideias elaboradas em momentos pregressos. Trabalhava com a premissa de que, sem subestimar o papel das ideias na história, o desafio estava em mostrar que, tal como as manifestações econômicas e sociais, as ideias são filhas do seu tempo (Soares, 2011, p. 88).

A partir destas compreensões, as quais apontam que as ideias em circulação estão diretamente associadas a sua historicidade e, portanto, a determinada experiência temporal, é preciso apontar que elas estão, do mesmo modo, associadas a sua espacialidade. A produção intelectual da América Latina possui uma vasta heterogeneidade, cada uma associada a suas particularidades espaciais e temporais. Dito isto, segundo Julio Ramos, "[...] al postular la heterogeneidad del sujeto literario latinoamericano en función de su modernización desigual, nos exponemos a varias críticas". A primeira seria a ideia de que o latino-americano estaria à margem em relação aos modelos europeus. "El problema con este tipo de lectura, bastante común en nuestros días, radica en la suposición de que "lo europeo" u "occidental" configura la inscripción de un origen, con un alto grado de pureza y homogeneidad." Segundo estas ideias, o 
latino-americano (considerado, então, como "terceiro mundo", subdesenvolvido, inclusive intelectualmente) deturparia esta pureza originaria ao representar, recitar ou simular o funcionamento dos códigos do "primeiro mundo" (Ramos, 2009, p. 167-168)².

Dicho de otro modo, el "origen" parecería contener marcas protuberantes de la "derivación" "paródica" o "antiestética. Lo que nos lleva a cuestionar ese tipo de narrativa histórica (lineal) incluso en Europa. Para nosotros la distinción es clave porque nos obliga a reconsiderar la postulación de la diferencia latinoamericana como efecto de la parodia de una plenitud (nunca comprobable) primeromundista (Ramos, 2009, p. 168).

A produção intelectual latino-americana é plural e heterogênea, ainda mais, possui especificidades epistemológicas. Mesmo a produção de saber europeia não é homogênea e, portanto, não é exemplo de uma linearidade característica e exemplar máxima do ocidente, a qual irradia modelos que deveriam estar sempre no âmago dos debates intelectuais. Para postular a diferença da literatura latino-americana, é preciso evitar a dualidade centro/margem a qual entende que a produção literária na América Latina é uma paródia ou uma imitação disforme de padrões europeus. Na produção intelectual realizada em espaços diversos, o que ocorre, portanto, é a circularidade de ideias entre espaços diversos e ressignificações através dos contatos (muitas vezes violentos) entre as diversas culturas.

A vasta produção intelectual entre os letrados na Primeira República esteve intensamente interessada em refletir acerca de aspectos sociais, políticos, culturais e históricos, muitas vezes a partir de um esforço direcionado para a consolidação de um Estado-Nação (Dutra, 2005, p. 83) $)^{2}$. Define-se, assim, um "modelo ideal de nação desejado: uma nação reconhecida pela sua diferença com outras nações e que participe do universal pela via da ilustração e, como veremos à frente, pelo progresso técnico-científico" (Dutra, 2005, p. 113-114). Com o protagonismo do elemento social, ou do "povo" como um singular coletivo, seus textos atentavam-se para os múltiplos matizes encontradas no país, ao mesmo tempo em que era preciso participar de forma mais intensa da comunidade internacional. Deste modo, a República instaurada em 1889, também resultado do desgaste do regime monárquico e de uma frente letrada republicana, abolicionista e liberal (a qual os chamados intelectuais - escritores e militantes das mais diversas atividades - participaram fortemente), sintonizava-se a uma perspectiva política que se difundiu no ocidente.

Segundo Sevcenko, grande parte da intelectualidade brasileira possuía grandes esperanças a respeito da resolução de parte de suas expectativas sociais, econômicas e políticas. Neste momento, "a palavra de ordem da 'geração modernista de 1870' era 'condenar a 
sociedade fossilizada' do império e pregar as grandes reformas redentoras: 'a abolição', 'a república', 'a democracia'. O engajamento se torna a condição ética do homem de letras", sempre em direção à modernização, republicanismo, democracia, abolicionismo, políticas liberais e ciências. No entanto, a obra destes homens de letras, durante o início do século XX, torna-se profundamente caracterizada por um grande clima de decepção em relação ao regime republicano, devido à consolidação da oligarquia rural, o pouco alcance do Estado em áreas além do sudeste, a falta de políticas públicas, o analfabetismo, a pobreza, as crises econômicas. Ainda assim, ao menos até a década de 1930, grande parte dos intelectuais continuaram produzindo diagnósticos e projetos que provocassem seus leitores a preocupar-se e refletir com o que seriam possibilidades de transformação social: "um mundo novo, liberal, democrático, progressista, abundante e de perspectivas ilimitadas, como ele se prometia" (Sevcenko, 1999, p. $78-79)^{3}$.

Como capital do país, o Rio de Janeiro foi, neste momento, um espaço privilegiado destas disputas, sendo local de muitas decisões políticas e administrativas, ainda que houvesse outros espaços de debate intelectual e produção editorial, como foi Salvador, na Bahia. Ainda assim, o Rio de Janeiro reunia parte significativa do capital cultural, sediando grande parte da imprensa, das editoras, cursos de formação, parte expressiva da produção literária, do movimento editorial e o comércio de livros, tornando-se local de sociabilidade da intelectualidade (Dutra, 2005, p. 23-24). Com a consolidação do que é entendido como uma república oligárquica no governo de Campos Sales, - presidente entre 1898 a 1902 - é especialmente neste espaço que também irá se assentar um desapontamento com o regime. Por mais que muitos destes intelectuais exercessem suas atividades em cargos públicos (como vereadores, senadores, deputados, diplomatas), sua participação na política, na administração governamental, era considerada por eles pouco expressiva frente á representação que esperavam ter (Sevcenko, 1999, p. 94).

Suas decepções traduzem-se na divergência de que seus prognósticos, reflexões e possíveis soluções não convergiam com os interesses das oligarquias, as quais utilizaram os cargos públicos como relações clientelistas, produzindo o que é conhecido como "República dos Conselheiros" (Sevcenko, 1999, p. 46). Para muitos destes intelectuais, grande parte destas deficiências diziam respeito à falta de preparo daqueles que ocupavam a máquina burocrática $e$ administrativa do país: os bacharéis. Há, nos trabalhos destes letrados, uma incisiva crítica ao que chamam de "bacharelismo", desaprovando uma cultura clientelista própria às elites brasileiras. Segundo este juízo, tais homens usavam seus títulos de bacharéis como "um talismã 
para os empregos públicos", preocupados especialmente com seus interesses particulares e não com a causa pública (Dutra, 2005, p. 180).

A denúncia do empreguismo e das redes de relações clientelísticas com fácil alcance ao aparelho de Estado e à política republicana, a qual desqualificaria a verdadeira aptidão e formação especializada para gerência dos negócios públicos, soma-se à denúncia do diploma como um simulacro, uma vez que os cursos frequentados pelo bacharel seriam incapazes de lhe dar um preparo prático e inteligente para a vida diária (Dutra, 2005, p. 180).

O espaço público, portanto, é entendido também como aquele onde se realiza a política a partir, dentre outras possibilidades, da imprensa e dos impressos. Como aponta Elias Palti, a respeito do novo léxico político que surge na América Latina, a partir da intensificação e ampliação da imprensa no início do século XX.

El periodismo aparecerá así como al mismo tiempo un modo de discutir y hacer política. Y esto infunde también una nueva conciencia a respecto de la performatividad de la palabra en el sentido de su "creatividad": la prensa periódica no sólo buscaba "representar" la opinión pública, sino que tenía la misión de constituirla como tal (Palti, 2007, p. 197).

Tal preocupação política pode ser observada através da análise de um artigo intitulado "Psicologia do Bacharelismo" no Almanaque Garnier de 1910, onde Eliana Dutra demonstra na denúncia ao bacharelismo um interessante posicionamento (Dutra, 2005, p. 35-36) ${ }^{4}$. Segundo o autor deste texto, o "povo inglês sabia escolher seus governantes, uma vez que seus dirigentes não eram somente doutores", e ainda, "os representantes dos interesses nacionais saem proporcionalmente de todas as classes, segundo a importância social de cada uma" (Dutra, 2005 , p. $180-181)^{5}$. Os homens de letras compreendiam-se como os mais preparados para a ocupação de tais cargos ou de algum tipo de atuação no que tange às decisões governamentais. Para eles, suas aptidões eram evidentes devido ás suas formações e intenso investimento na compreensão das causas públicas e dos problemas nacionais, como aponta Sevcenko (Sevcenko, 1999, p. 45-46), Gomes (Gomes, 2009, p. 25-27) e Hansen (Hansen, 2000, p. 28).

Segundo Habermas, o surgimento das ideias de "causas públicas" e "interesse público", apenas tornaram-se parte de uma linguagem política quando diversos processos históricos constituíram o confronto entre "Estado" e "sociedade" na modernidade ocidental.

Esse pano de fundo histórico forma também o contexto para o interesse específico em uma esfera pública que somente é capaz de assumir funções políticas na medida em que possibilita aos cidadãos da economia, na qualidade de cidadãos do Estado, estabelecer compromissos ou universalizar seus interesses e torna-los tão efetivos a ponto de o poder do Estado se transformar no medium fluido de uma auto-organização da sociedade (Habermas, 1984, p. $51)$. 
A partir das categorias de Pierre Rosanvallon, compreendo que, se há alguma participação dos homens de letras na política, essa entendida como o exercício da representação partidária e do poder administrativo propriamente dito a partir dos cargos públicos, tais letrados mantêm-se intensamente mais ativos no plano do político. A saber, tal plano se constitui como uma "modalidade de existência da vida comum" e "uma forma de ação coletiva que se distingue implicitamente do exercício da política" - trata-se, enfim, da vida pública, da representatividade, daquilo que constitui a polis (Rosanvallon, 2010, p. 72-73). Tais atitudes demonstram-se como "melancólicas" onde, apesar de possuírem certa desilusão e descrença, ainda assim investem em um vigoroso engajamento em suas atividades. Isto, por entenderem que é necessário comprometer-se com a vida pública e o espaço intelectual. Neste sentido, o conceito de melancolia é de grande importância para nossas concepções.

[...] compreendemos então que (a) no interior de um "tempo histórico" marcado pela experiência da aceleração [...] os homens são provocados a perceber e a refletir sobre o tempo a partir da compreensão de que ele é um agente autônomo e imediato de transformações. E, como desdobramento dessa necessidade, evidencia-se uma compreensão ontológica específica, a de que a existência humana é deveniente, ou seja, que ela se transforma incessantemente. E mais: (b) no interior de um "tempo histórico" marcado pela aceleração, no qual vigora a compreensão (e/ou impressão) de que a existência humana é determinada pela deveniência, torna-se adequada a percepção antropológica de que o sofrimento é próprio aos homens em geral. E, por fim, (c) dá-se, assim, a conformação de um "clima histórico" melancólico (Rosanvallon, 2010, p. 170-171).

Coloca-se, assim, a importância do estudo das obras destes autores, não porque são apenas "expressões do pensamento, mas porque eles representam a formalização de um momento histórico, político ou filosófico específico" (Rosanvallon, 2010, p. 46-47). Esta história das ideias ou história intelectual não pode ser limitada à análise de grandes textos, no entanto, estes trabalhos "ilustram as questões suscitadas em determinado período histórico e as respostas então oferecidas" (Rosanvallon, 2010, p. 44-45). E mais, a compreensão destas ideias são fundamentais para que possamos refletir e nos movimentar melhor no interior de nosso próprio tempo (Rosanvallon, 2010, p. 33-35). Nesta temporalidade, tanto na América Latina como na Europa, o campo intelectual, a sua produção (livros, discursos, artigos de jornais e revistas, peças de teatro, etc.) e o campo político não podem ser separados ${ }^{6}$, tanto empiricamente como teoricamente. $^{7}$

Ou seja, uma concepção [de campo] que não se restringe à atuação formal em termos de funções representativas (executivas ou legislativas), podendo-se estender: 1) à defesa de ideias elou à formulação de projetos políticos-culturais, 
mais ou menos bem acabados, que se manifestam pela produção de obras dos mais diferentes tipos, dirigidas aos mais diversificados públicos; 2) à ocupação de cargos/funções em loco privilegiados, fossem eles públicos (o funcionalismo público, uma espécie de segunda 'pele' do intelectual desse período), ou privados, menos valorados pela bibliografia, mas não necessariamente menos importantes (Gomes, 2009, p. 25-27).

Nesta historicidade, a produção do saber se encontrava engajada a projetos pragmáticos, em reflexões e análises que se direcionavam ao corpo social. E isto, tanto nas artes como nas ciências em geral, de modo que, muitas vezes, a história ganhava centralidade para a compreensão de tal sociedade.

O ensaio $O$ colono preto como fator da civilização brasileira, de Manuel Querino, se insere na perspectiva do político a partir de um esforço em mencionar o silenciamento no interior das narrativas históricas quanto a contribuição da população negra (especialmente aquela escravizada) na formação social, econômica, cultural e afetiva do Brasil. A desvalorização da população negra como fator do progresso moderno no Brasil acabaria por acarretar consequências discriminatórias no regime Republicano. A partir disto, Querino produz uma escrita da história focada nas mulheres e homens negros durante o período colonial, também como escravizados, mas como aqueles que resistiram a instituição escravista, trabalharam a partir de técnicas trazidas das etnias africanas onde foram traficados, produziram o capital material necessário para viabilizar a colônia e a posterior formação do Estado-Nação brasileiro. Segundo ele, o contato com os povos árabes teria produzido entre as culturas africanas uma série de técnicas, saberes e conhecimentos importantes na realização de diversas atividades, ofícios e ocupação de espaços.

A história nos afirma que, muito antes da era cristã, os árabes se haviam introduzido nos sertões do Continente Negro, e com maior atividade no século VII. Missionários muçulmanos internaram-se em alguns pontos da África, semeando os germens da civilização, abolindo a antropofagia e a abominável prática dos sacrifícios humanos. Levando-se em conta o grau de cultura atingindo por esses invasores, com tais predicados, não resta a menor dúvida de que foram eles os introdutores dos conhecimentos indispensáveis ao modo de viver do africano nas florestas, nas planícies, nas matas, nas montanhas, vigiando os rebanhos, cultivando os campos, satisfazendo assim as necessidades mais rudimentares da vida. Acrescente-se a essa circunstância a fundação de feitorias portuguesas em diversos pontos do Continente, e, chegarse-á à conclusão de que o colono preto, ao ser transportado para a América, estava já aparelhado para o trabalho que o esperava aqui, como bom caçador, marinheiro, criador, extrator do sal, abundante em algumas regiões, minerador de ferro, pastor, agricultor, mercador de marfim etc. Ao tempo do tráfico, já o africano conhecia o trabalho da mineração, pois lá abundava o ouro, a prata, o chumbo, o diamante e o ferro. E como prova de que ele de longa data conhecia diversas aplicações materiais do trabalho veja-se o que diversos 
exploradores do Continente Negro dizem de referência ao que sobre o objeto encontraram (Querino, 2017, p. 5).

Estaria aí a razão pela qual a administração portuguesa traficava escravos africanos, a técnica e o conhecimento característico de suas culturas. Em sua perspectiva, agiram também como colonos, especialmente porque havia certa repulsa por parte dos colonizadores europeus para a realização dos trabalhos braçais, que eram forçados naqueles que eram escravizados.

A ideia de riqueza fácil banira da mente do aventureiro faminto o amor do trabalho, que era considerado uma função degradante. Por mais respeitável que fosse a ocupação era ela desprezada pelos reinóis de pretensões afidalgadas. Esta circunstância, porém, favoreceu aos homens de cor nas aplicações mecânicas, e mesmo algumas liberais, cuja aprendizagem valia como um castigo infligido aos humildes, como se fora ocupação infamante. Só a estes era dado trabalhar (Querino, 2017, p. 8).

O projeto da colônia portuguesa nas Américas não teria sido possível sem a produção de capital e material a partir do trabalho realizado por mãos negras, ainda mais porque uma grande parte dos homens brancos que se instalaram de início nas colônias eram criminosos ou indivíduos indesejados, ou seja, "sem isso, difícil senão impossível era pegar no País a colonização com elemento europeu, tanto mais quanto ao iniciar-se esta, afora os serventuários da alta administração, as primeiras levas eram de degredados, de indivíduos viciosos e soldados de presídio" (Querino, 2017, p. 7-8).

A administração portuguesa, portanto, os colonos brancos, estavam particularmente interessados em possibilidades de enriquecimento rápido, movidos por sentimentos de ganância: "O parasitismo alçou o colo, deu combate em campo raso com o apoio do governo, que participava dos lucros auferidos" (Querino, 2017, p. 4). Assim como para Bomfim, produziram uma espécie de sistema "parasitário", apenas produzindo e importando recursos para a metrópole e seus representantes nas colônias. Neste processo, o financiamento material da intelectualidade, da educação, da política, etc., teriam sido feitos a partir do trabalho de mulheres e homens negros.

Mesmo a partir de tamanha violência institucionalizada, comunidades negras, como os quilombolas, baseadas em estruturas de sociabilidade, teriam sido estruturadas como formas de resistência, demonstrando a grande capacidade de organização social orgânica entre estes sujeitos. A partir deste argumento, Querino faz um interessante paralelo entre os escravos gregos, e os escravos negros no Brasil. Ainda que possuíssem algum tipo de formação, os gregos escravizados não teriam tido o mesmo ímpeto de realização de uma organização comunitária, ou 
seja, as comunidades quilombolas produziram uma administração política funcional $e$ independente e sociabilidades funcionais, além de providenciar as defesas necessárias.

Os escravos gregos eram instruídos, tanto nos jogos públicos como na literatura, vantagens que o africano escravizado na América não logrou possuir, pois o rigor do cativeiro, que não consentia o menor preparo mental, embotava-lhe a inteligência. Sem embargo, mostrou-se superior às angústias do sofrimento, $e$ teve gestos memoráveis de revolta, buscando organizar sociedade com governo independente. Conhecia as organizações guerreiras e se predispôs para a defesa de sua cidadela de Palmares, e para as incursões oportunas no território vizinho e inimigo (Querino, 2017, p. 13-14).

Querino organiza em seu texto uma preocupação quanto a divulgação, o reconhecimento e valorização da população negra enquanto sujeitos da história brasileira. Dito isto, o espaço do político em seu texto se encontra na denúncia de narrativas históricas que desprezam e rejeitam a comunidade afro-brasileira como grande agente no interior das experiências do passado e do seu presente, problema de grande intensidade no início do século $\mathrm{XX}$, especialmente das pequenas comunidades letradas no Brasil compostas, em geral, por homens brancos.

O autor de O Brasil na História compreende que, para que haja solidariedade entre os sujeitos, de modo que possam criar e investir em projetos (agir coletivamente) é necessário que haja experiências históricas sedimentadas como tradição, de modo a estimular, potencializar a ação. Do mesmo modo, sempre há a possibilidade de que se constituam tradições desanimadoras, desestimulantes. Sobre o conceito de tradição, Bomfim discorre:

São almas que se continuam através das idades; são os veios que traçam o viver da humanidade. Ou, melhor, é a trama viva onde se tecem as consciências, para todos os efeitos de realização humana - moral, política, religião, arte, produção econômica... que tudo se faz como expressão patente de tradições. A sociedade humana existe e se desenvolve em sociedades parciais, de valor nacional, que englobam agrupamentos menores, ou de valor mais restrito. E a vida da humanidade se reduz ao desenvolvimento desses agrupamentos, em que se incorpora a vida de uma tradição. Destarte, é a tradição mesma que se desenvolve, e progride, e se apura, como se amesquinha, e decai, e deperece (Bomfim, 1930, p. 18-19).

Caso o Estado-Nação moderno não consiga fundamentar narrativas históricas potencializadoras, portanto, sendo desestimulantes, é possível que ocorra a limitação da capacidade de ação dos sujeitos em sua sociedade.

A história seria um luxo perdido, inútil dispêndio de inteligência a que o homem não se entregaria, si não houvera a tradição, com a sua indiscutível utilidade - estimulo e orientação. Com esta compreensão cinemática da tradição, tudo nos parece lógico: ela é a forma de uma marcha orientada. A realização social se faz, necessariamente, em esforços individuais; mas é na 
tradição que se definem as possibilidades de harmonia entre o individuo $e$ o conjunto social. Podemos considerá-la, pois, como a própria sociedade em continuação, tanto se condensam nela, as afinidades ativas, graças às quais se mantem e se desenvolve, em cada grupo, a vida social (Bomfim, 1930, p. 14).

Sendo assim, no nível individual, "a realização é o constante resultado da fé que o indivíduo tem na ação a desenvolver" (Bomfim, 1930, p. 9). O político, o envolvimento cotidiano dos sujeitos na potencialização de suas capacidades de ação (associados a suas demandas, identidades, representações, etc.) depende, portanto, de alguma relação de intimidade com suas compreensões e narrativas históricas, compartilhados no interior de sua(s) identidades e identificações (de grupos, étnica, da "nação", região, etc.). Para agir, individualmente e coletivamente, é necessário o compartilhamento de histórias, de passados, localizando-se espacialmente e temporalmente, produzindo então, projetos e prognósticos.

Nas consciências ainda opacas, onde tal intuição ainda não alcançou representação definida, é preciso, então, o motivo concreto, imediato, o talismã explicito, forma tangível, e que vale como objeto direto de confiança, a que a alma ingênua e primitiva dá a sua crença, para satisfazer a essa absoluta necessidade - de confiar no próprio valor para a ação a que se entrega. Se não, em que ente de razão se firmaria a sua vontade para dar o esforço indispensável ao êxito?... E não poderia ser de outra forma. O homem, na ação humana, é um valor de consciência. Tanto vale dizer: para os fins da atividade inteligente e social, todos os motivos têm que tomar um aspecto consciente (Bomfim, 1930, p. 8-9).

A carência destas narrativas corrói a potencialidade de ação dos sujeitos e suas capacidades no interior de suas relações comunitárias e sociais. Uma dilatação de suas compreensões acerca das experiências passadas, de outras narrativas históricas, amplia o que Bomfim chama de "valor de consciência", uma necessidade pulsante de engajamento associado à ampliação do saber histórico coletivo. Nesta perspectiva, Bomfim produz uma interessante teoria da cognição, da capacidade de aprendizado humano:

Já havia história, e a humanidade era, ainda, uma qual nebulosa de consciência social, até que a síntese - inteligência/sentimento foi bastante coesa e lucida para examinar-se a si mesma, na prescruta de seus processos de realização, e dos próprios diferentes modos de ser. As respectivas verificações tiveram valor de doutrinas na interpretação do mundo político e social. Compenetremo-nos desta primeira teoria de progresso, e reconheceremos que o entendimento humano não teria ido até ela sem reiterados julgamentos morais cada vez mais nítidos e profundos como exige a concepção de justiça, consagração final do que a filosofia do século XVIII reclamava (Bomfim, 1930, p. 23).

A inteligência humana (capacidade de refletir acerca dos fenômenos e objetos) associada a sua capacidade afetiva (de experimentar através do corpo, dos sentidos, de se relacionar com 
entes e objetos) teriam se intensificado na espécie humana a ponto de que a análise das possibilidades do agir, enquanto processo de realização individual e social, teriam se tornado uma operação necessária e natural. Tais operações, em um esforço de produção de uma narrativa coesa para tentar fornecer estas condições de realização, teriam se configurado nas teorias políticas e sócias, ou ainda, em doutrinas.

De maneira quase fenomenológica, Manoel Bomfim argumenta que a necessidade urgente e material da vida humana se encontra na base dos processos históricos ou na fundamentação das instituições: "Quando um processo social ou instituição histórica tem valor natural e corresponde a necessidade indeclinável, encontramos sempre, a dar lhe base, um iniludivel instinto, pois que o instinto significa exigência direta e formal da própria vida" (Bomfim, 1930, p. 13). Deste modo, naturalizamos os processos históricos como algo que simplesmente se deu pelo correr diário. A constituição de narrativas históricas, para orientar e estimular o agir, seriam quase como uma constante antropológica, uma preocupação que se faz presentes em todas as sociedades e culturas no tempo e espaço:

Ora, desde os primeiros dias da humanidade, como no que ainda existe de almas primitivas, quando a ação exprime imediatamente imposição instintiva, verificamos o zelo pela tradição, com o ânimos a exaltarem-se nela, a levaremse no influxo e na orientação que dela recebem (Bomfim, 1930, p. 13).

A vida social dos sujeitos se desenrola, portanto, através do que ele chama de "instinto", ou seja, pela necessidade diária de ação imposta pelas características das realidades cotidianas. As possíveis relações com as experiências passadas em formato de tradição, caso sejam constituídas para tal, podem animar e potencializar este agir em direção ao que se quer alcançar coletivamente. Seria esta a definição de progresso para Bomfim, um pacto social ou comunitário a respeito do que se considera progredir em determinado espaço e tempo.

Portanto, não há em seu argumento a percepção linear do tempo e dos processos históricos, mais ainda porque Bomfim entende que a perspectiva de realização, a ideia de progresso (cara ao ideal civilizacional moderno), não se realiza necessariamente, como uma filosofia da história. Para ele, "na realidade objetiva, não há progresso, pois não poderia haver melhor, nem pior". Bomfim entende que o podemos conceber é que "há evoluções; mas, conscientes, no orientar e animar nossos esforços, agimos como se houvera, de fato, progresso, $e$ conduzimos a ação para aquilo que, no subjetivo da espécie, consideramos como melhor" (Bomfim, 1930, p. 24). Portanto, o progredir-se, o desenvolver-se, se define a partir de interesses e necessidades associadas a grupos e sujeitos historicamente constituídos, ou melhor, são valores construídos temporalmente e espacialmente. 
As narrativas históricas (especialmente a escrita da história pelos historiadores) fazem parte da composição da tradição e da memória como um fator do ético e do político. Neste sentido, trata-se da "tradição nacional em si mesma como indicação das possibilidades no conjunto humano" (Bomfim, 1930, p. 25). Para Bomfim, a tradição intensifica e unifica ideais, expectativas e metas relativamente comuns a uma sociedade, possibilidades as quais um grupo pode se organizar para atingir, assim, constituindo progresso. $\mathrm{O}$ saber histórico possibilita atingir o que é considerado melhoria a um grupo que compartilha alguns elementos culturais, e ainda, anima a expandir tais melhorias a estes indivíduos. Por isto, para Bomfim, a educação seria um elemento essencial para intensificar as possibilidades de ação e transformação dos sujeitos. Para o autor de O Brasil na História, nas narrativas acerca das experiências históricas encontram-se as perspectivas de transformação da "tradição" e a capacidade de potencialização dos "motivos de confiança": "só aí, podemos achar o que nos explique o presente, e as virtualidades discerníveis no futuro" (Bomfim, 1930, p. 25).

\section{Engajamento e escrita da história}

É preciso sublinhar que muitas das concepções da escrita da história moderna (análise de fontes, crítica documental, uso de métodos, fundamentações teóricas, citações e referências, etc.) eram cruciais em muitos dos ensaios históricos do final do século XIX e início do século XX. O trabalho de Capistrano de Abreu foi tomado por muitos destes autores como um grande exemplo desta possibilidade de escrita da história. Capistrano procurou fundamentar sua narrativa através da pesquisa, do uso de fontes, da crítica documental, do uso de métodos e perspectivas teóricas. Simultaneamente, desempenhou em sua escrita certo posicionamento intelectual político, além de uma percepção afetiva e do uso de recursos estéticos em sua escrita. Segundo Hansen, com esta abordagem, Capistrano cumpria uma expectativa comum entre muitos de seus pares, que era o de acrescentar o elemento subjetivo, o artístico e o pedagógico na escrita da história: "Há muito se reivindicava uma escrita da história do Brasil que levasse em conta outros recursos, explicativos e narrativos, que permitissem superar a mera exposição dos 'fatos"' (Hansen, 2000, p. 47).

As mesmas expectativas e as mesmas concepções modernas de história se encontravam no livro didático História do Brasil (1901) de João Ribeiro em suas várias edições para diversos níveis de escolaridade. Patrícia Hansen aponta que seu sucesso e sua importância no ensino do Colégio Pedro II demonstra a relevância da nova concepção de história. Tal possibilidade de escrita da história estava pautada nos princípios pragmáticos lógico-formais e estéticos, ambos 
ético-políticos, ou seja, engajados com um compromisso de refletir, agir sobre a realidade, mesmo que assumindo seus limites sociais, históricos e individuais (Gumbrecht, 2010, p. 1314) $)^{8}$. Capistrano e Ribeiro se orientam pela mesma compreensão de história: científica, teórico/metodológica, uso de documentações somadas aos aspectos filosóficos, hermenêuticos e afetivos. No entanto, Capistrano se focava mais intensamente na narrativa descritiva, na pesquisa documental e no método. João Ribeiro privilegiava a interpretação e a reflexão filosófica, com seu fim pedagógico realizado no ensino - devido a isto, a sua História do Brasil se dirigia mais especificamente a seus pares educadores (Hansen, 2000, p. 65-67).

Capistrano e Ribeiro acrescentaram, atualizaram e substituíram parte do cânone da obra de Varnhagen e Manuel de Macedo. Estes dois últimos autores foram, até então, principais referências no ensino de história, ainda no final do século XIX, onde, no geral, os fenômenos populares (bandeiras, minas, entradas, criação de gado, etc.) eram excluídos em prol de uma história da política voltada para a legitimação da monarquia. Capistrano critica a historiografia com enfoque na administração por esta evitar a tematização das realidades da população (Rosanvallon, 2010, p. 11-12) ${ }^{9}$. Para este historiador, era preciso beneficiar na escrita da história "a terra e as gentes que a habitavam" (Hansen, 2000, p. 70-71). Ainda assim, é preciso lembrar que o formato educacional promovido, nesta perspectiva, se voltava para a formação de meninos brancos, filhos de uma elite entendida como aqueles os quais poderiam "dirigir" o país (Hansen, 2000).

A concepção de história e o formato da narrativa histórica "decorriam, em parte, das novas exigências políticas desse novo regime", ou seja, de uma reflexão engajada com o político, com a república (Gomes, 2009, p. 24). Nesta experiência, era preciso um passado para se orientar e um futuro como projeto, $e$ isto porque se tratava de uma experiência temporal profundamente acelerada, de um novo regime político o qual convivia com uma realidade inédita, a da abolição e a da república. Há, nestes esforços, uma relação fundamental entre a escrita da história nacional e a consolidação de uma cultura política republicana, uma cultura cívica patriótica capaz de criar cidadãos.

No Brasil, pode-se desde já assinalar que a ação política corre menos por conta de políticas governamentais do que por iniciativa de uma intelectualidade, organizada de múltiplas formas, pressionando as autoridades políticas $e$ participando, em especial nos anos 1920, na administração dos estados, de medidas reformadoras no campo da educação, especialmente após a formação da Associação Brasileira de Educação (ABE), em 1924 (Gomes, 2009, p. 8889). 
Além desta postura política, há uma preocupação ética que quer debater a respeito das normas e valores consolidados nas diversas esferas e espaços da sociedade até então. Devido a tudo isto, a alfabetização e a educação foi tema de grande debate, onde a ideia da "prosperidade e do progresso econômico" são condições "para o progresso intelectual, moral e cívico da nacionalidade, assegurado pela abertura de escolas e pelo compromisso com a instrução e com a difusão dos saberes científicos" (Gomes, 2009, p. 24). Não se trata de uma educação qualquer, mas um ensino que procura tematizar incessantemente a história, especialmente a história do Brasil, apesar de que, o sistema educacional se definia por um esforço voltado para a formação de uma elite. É importante lembrar que, para muitos autores, a alfabetização e a leitura são instrumentos de poder. A indiferença em disponibilizar esta possibilidade, intensifica a exclusão social dentro de uma lógica liberal a qual não distribui perspectivas para o acesso de todos à escolarização. Como cita Erica Schlude Wels ao apontar esta questão:

Silvia Castrillón sustenta o quanto a leitura, sozinha, não é boa ou ruim em si mesma, mas sim um direito histórico e cultural, logo, político. [...] Para Castrillón, numa lógica de formação de mercado consumidor, cabe à população de muitos países sul americanos considerar a leitura um real instrumento para seu benefício, sendo de seu interesse apropriar-se dela. Somente assim, chegaríamos a uma democratização da cultura letrada (Wels, 2016, p. 121).

Portanto, muitos destes autores preocupavam-se também em produzir um conhecimento escolar, escrevendo manuais e livros voltados para as escolas normais. Além disso, atuavam muitas vezes como professores, como foi o caso de Manuel Querino e Manoel Bomfim.

Nesse sentido, é bom destacar desde o início os sólidos vínculos existentes entre o traçado das características de saber erudito da história e seu valor pedagógico, ou pragmático, como também se usava [...]. Quer dizer, a história, como disciplina "moderna", afirmava, exatamente pelo tipo de concepção que então se construía e solidificava sobre sua identidade, uma feição que era, ao mesmo tempo, erudita/científica e ensinável/pragmática, indissociavelmente (Gomes, 2009, p. 10).

Do mesmo modo, tais preocupações ético-políticas consistiam em uma (entre outras) possibilidade nesta historicidade ${ }^{10}$. Nos ensaios, tais preocupações não são apresentadas somente a partir de uma perspectiva lógico-formal (sentido), mas também por pragmáticas estéticas (presença) que procuram, através da linguagem, proporcionar ao leitor experiências de caráter sensorial e afetivo. Neste sentido, escolhas teóricas e metodológicas são voltadas à operacionalização do conhecimento, mas também a uma prática sensitiva. 
É interessante notar que, se o hábito de ler é o que garante a condição de se conhecer o Brasil, é o adequado conhecimento do país o que vai permitir que uma imagem global do Brasil seja construída, e que elementos de identificação sejam disponibilizados aos leitores de forma que 'a unidade moral e social' da nação possa ser efetivada. E que questões do tipo o que é o Brasil e o que é ser brasileiro ganhem efetivamente um novo sentido, a luz de um reconhecimento cultural possibilitado por um patrimônio literário comum (Dutra, 2005, p. 97).

Uma significativa parte dos letrados do início do século XX - precedida pela chamada "Escola de Recife", pela "Geração de 1970" - se reuniu com outros intelectuais no Rio de Janeiro e em vários espaços de interação, entre eles, a Academia Brasileira de Letras, o Colégio Pedro II, o Instituto Histórico e Geográfico e em torno do Ministério das Relações Exteriores sob a direção do Barão do Rio Branco. Muitos deles se formavam no nordeste do país e lá criavam outras possibilidades editoriais e espaços intelectuais, ainda que muitos realizassem suas atividades no sudeste. Portanto, é necessário pontuar que Bomfim nasceu em Aracaju, tendo vivido durante a sua carreira no Rio de Janeiro ${ }^{11}$. Já Querino nasceu em Santo Amaro, atuando intelectualmente e politicamente na Bahia ${ }^{12}$.

Nestes espaços, muitos destes intelectuais atuavam na historiografia, educação, em militâncias, como jornalistas e diplomatas após, muitas das vezes, se formarem ou passarem por escolas de medicina, direito ou engenharia (Dutra, 2005, p. 25). Em suas formações diversas, há a produção de uma forte crítica a uma República problemática, que não assegura oportunidades e pouco empreende para a realização dos seus valores em torno da ideia do Estado-Nação ${ }^{13}$. O conhecimento $e$ as artes são apontados como formas para alcançar o projeto de ação $e$ desenvolvimento para estas perspectivas.

No entendimento de João Ribeiro, o Brasil em suas "feições e fisionomia própria", o que ele é, o seu ser ou "essência", certamente não poderiam ser evidenciados pelo estudo da administração portuguesa ou pela narração das relações políticas internacionais. Para a compreensão do país era necessário se atentar àqueles os quais as ações promoveram a "grandeza territorial" e "preencheram com vida" o país: o Brasil "deriva do colono, do jesuíta e do mameluco, das ações dos índios e dos escravos negros" (Hansen, 2000, p. 73-74).

Destacando os resultados que não eram "caracteristicamente" estrangeiros, João Ribeiro, por oposição, procurava identificar o caracteristicamente nacional. Todavia, essa busca de uma história que "é ainda hoje a mesma presente", me parece estar amplamente fundamentada sobre a noção de "típico", que é um dos traços distintivos de uma vertente da produção historiográfica de origem alemã do século XIX, a Kulturgeschiche (Hansen, 2000, p. 73-74) ${ }^{14}$. 
No que tange a Manuel Querino, sua escrita da história possui uma série de procedimentos considerados importantes para uma produção científica desde o século XIX. Seu texto, publicado primeiramente em 1918, para o sexto Congresso Brasileiro de Geografia, faz o uso de fontes, crítica e análise documental, cita e debate a partir de outros autores, como historiadores, sociólogos e polígrafos em geral. Há também a preocupação em não manter a escrita somente atada a uma normatividade, discorrendo muitas vezes de forma mais livre, intuitiva. Ainda mais do que isso, possui elementos daquilo que chamamos aqui de presença, ou seja, a partir de uma estética, onde procura apontar para os sentidos e afetividade do leitor, tentando presentificar experiências passadas, mencionando a materialidade do espaço, das cores, das texturas, dos corpos, das dores, dos sentimentos. Nesta mesma perspectiva, Querino também traz versos de canções e poemas para seu texto. Assim, é possível se aproximar de forma mais íntima de seu esforço ético-político, de refletir, de tocar o leitor a partir da narrativa, por exemplo, a respeito das violências da escravidão de pessoas negras no Brasil.

Ora era o escravizado preso, conduzido pelo capitão do mato, que o obrigava a acompanhar os passos da cavalgadura; ora eram dois possantes escravizados de azorrague em punho a açoitarem a um parceiro, cortando-lhe as carnes, até expirar, na presença do algoz, que assistia satisfeito àquela cena de canibalismo, vaidoso da sua incontida prepotência. Ali, um escravizado preso ao tronco e às vezes pelo pescoço, sob a ação do suplício da fome e da sede, sem conseguir alcançar o alimento ou o vaso de água colocados propositadamente fora do alcance das mãos, enquanto os roedores mordiamlhe os pés. Depois, é uma vítima que esteve no vira-mundo, amarrada ao costado de um animal e mandada atirar longe do povoado, para sucumbir à míngua de qualquer recurso (Querino, 2017, p. 10).

Sua escrita presentifica a tortura de ser atado enquanto é obrigado a acompanhar a velocidade do cavalo em que se está preso, da humilhação em forçar outros escravos negros a açoitar o outro, como se fosse um terrível ato de canibalismo, da carne exposta pelas chicotadas, do sangue espirrado, do poder exercido pelo algoz, do tronco, da fome e da sede, dos animais mordiscando o corpo supliciado, do sofrimento extremo. E continua, acerca da saudade, pela vontade de liberdade, tratando da materialidade dos espaços de onde foram traficados membros das etnias africanas, mencionando lugares áridos, do vento forte, de cascatas, de florestas, da busca da liberdade no "íntimo de sua alma".

A nostalgia apoderou-se dos infelizes; e o filho do deserto adusto, recordando a impetuosidade do vento, o murmúrio brando da cascata, o eco adormecido das florestas do torrão natal, angustiado pelo rigor da escravidão cruel, mortificado de pesares, uma única ideia lhe perpassava na mente, um pensamento único lhe assaltava o espírito: a ideia sacrossanta da liberdade que ele tinha gravada no íntimo de sua alma (Querino, 2017, p. 10-11). 
Querino preocupa-se em escrever uma história politicamente engajada na valorização da contribuição dos sujeitos negros para a constituição do Brasil, que apesar de escravizados, resistiram às violências imputadas a eles e realizaram infinitos ofícios e diversos trabalhos os quais o colono branco possuía aversão. Os trabalhos realizados por mãos negras, muitas das vezes a partir do conhecimento técnico trazido das etnias africanas, teriam constituído o Brasil moderno. Também teriam realizado uma importante cultura afetiva a partir de seus relacionamentos de proximidade com a família na "casa grande"15. A produção de riquezas materiais por aqueles que foram escravizados está, inclusive, na raiz do financiamento da cultura intelectual brasileira, da política (das ocupações administrativas e representativas do Estado), do clero, da defesa militar, já que o trabalho realizado por pessoas negras produziram o capital necessário para a educação de homens brancos. Com este intuito, o autor trata da necessidade de mencionar estes sujeitos como aqueles que conceberam grande parte das estruturas materiais no Brasil (e não somente como escravizado) para que se produza uma escrita da história de rigor em relação ao passado.

Quem quer que compulse a nossa história certificar-se-á do valor e da contribuição do negro na defesa do território nacional, na agricultura, na mineração, como bandeirante, no movimento da independência, com as armas na mão, como elemento apreciável na família, e como o herói do trabalho em todas as aplicações úteis e proveitosas. Fora o braço propulsor do desenvolvimento manifestado no estado social do país, na cultura intelectual $e$ nas grandes obras materiais, pois que, sem o dinheiro que tudo move, não haveria educadores nem educandos: feneceriam as aspirações mais brilhantes, dissipar-se-iam as tentativas mais valiosas. Foi com o produto do seu labor que os ricos senhores puderam manter os filhos nas universidades europeias, $e$ depois nas faculdades de ensino do País, instruindo-os, educando-os, donde saíram veneráveis sacerdotes, consumados políticos, notáveis cientistas, eméritos literatos, valorosos militares, e todos quantos ao depois fizeram do Brasil colônia, o Brasil independente, nação culta, poderosa entre os povos civilizados (Querino, 2017, p. 21).

Para Manuel Querino, a escrita da história, mais do que um rigor científico na produção de representações sobre o passado social, econômico e político, precisa representar o cultural, o afetivo, o sentimental, os corpos dos sujeitos que se encontraram nestas experiências. Isto deveria ser realizado, portanto, não somente através do lógico-formal (do sentido), mas também a partir da presença. Mais ainda, as narrativas e representações das experiências passadas precisam estar engajadas no presente onde se encontram. No caso de $O$ colono preto como fator da civilização brasileira, a escrita da história deveria estar presente procurando evidenciar a violência imposta por séculos à população negra, sofrimento constituído historicamente e institucionalmente, onde as consequências deste processo ainda sujeitavam negras e negros a violências no período Republicano. 
Para Bomfim, é necessário que se tenha consciência das energias que estimulam, mas também apurá-las, ou seja, seria preciso acentuar os elementos da tradição que estimulam, motivam o progresso social e a sociabilidade. Trata-se de um processo sempre em movimento, $e$ a escrita da história também precisa mediar e dar acesso às possibilidades potencializadoras do passado que podem se realizar. Portanto, a intensificação de uma distância em relação às experiências passadas acaba por reduzir perspectivas de futuro.

E compreende-se que todo progresso mental e social, para cada grupo humano, tem de fazer-se como reforço e apuro dos valores de consciência definidos na respectiva tradição. Dai a necessidade de buscar todos os fatos em que se torna sensível essa mesma tradição, e que as consciências mergulhem nela, até que a incorporem $e$ lhe deem vida: a vida indispensável para o prosseguimento de fados próprios, pela plena expansão dos dons já revelados no passado (Bomfim, 1930, p. 12).

Em suas perspectivas, não há a noção que constrange uma ideia de subjetividade em favor de objetividades. Para ele, as experiências afetivas precisam ser representadas, pois, além de serem parte importante dos passados humanos, se encontram inseparáveis, diretamente associados a constituição humana. Seria este, o espaço da presença em seu texto, a necessidade de representação do sensorial e afetivo, além da necessidade humana de experiências históricas tangíveis na sua cotidianidade para a orientação e a manutenção da pulsão para o agir. Mais ainda, os aspectos sentimentais são indissociáveis da necessidade de norteamento humano, das suas capacidades e estimulo à ação.

Desta sorte, crea-se na história, mais do que em qualquer das instituições concretas, o mundo onde se encontram os desejos e as realizações, atravez dos tempos e das classes sociaes. Vão com ella os sentimentos dominantes $e$ fecundos, sem que isto lhe contradiga a funcção essencial, antes beneficiando-a, pois que o sentimento é o próprio estímulo na consciência. E vemos, então, como as novas necessidades cream novas constituições, renovada a organização das forças essenciais no agrupamento humano [...]. Para tanto, exige-se da história rigorosa coordenação de perspectivas vívidas, planejadas em lógica (Bomfim, 1930, p. 38).

As narrativas históricas, especialmente a escrita da história pelos historiadores, fazem parte da composição da tradição como um fator do ético e do político: "Tradição nacional em si mesma como indicação das possibilidades no conjunto humano". A tradição poderia, portanto, unificar ideais, expectativas e metas relativamente comuns a uma sociedade, ou seja, somar possibilidades as quais um grupo pode se organizar para atingir o que se considera (temporalmente e espacialmente) como progresso. Pode, assim, proporcionar atingir o que é considerado melhoria a um grupo que compartilha alguns elementos culturais $e$, ainda, animar a 
expandir tais melhorias para estes indivíduos. Por isto, para ele, a educação seria um elemento essencial para disponibilizar estas possibilidades. Em seu ensaio, na história encontram-se as tradições, experiências e "motivos de confiança": "só aí, podemos achar o que nos explique o presente, e as virtualidades discerníveis no futuro" (Bomfim, 1930, p. 25).

Em o Brasil na História, o passado aparece como um influxo de experiências que aponta possibilidades no tempo. É preciso conhecer parte destas experiências as quais conferem identificação, solidariedade e identidade, que dizem respeito ao povo ao qual pertence (tradição) para tentar responder a este influxo de forma mais "consciente", buscando se orientar, criar projetos de ação a partir destes passados: "Representamos esta história em todas as formas do passado que devem subsistir. Atestamo-lo na nossa própria vida. Como admitir que nos podemos subtrair ao seu influxo?" (Bomfim, 1930, p. 26). Este espaço de ação do cotidiano, do político, diz respeito ao esforço de conservação social a partir das necessidades urgentes $e$ pulsantes da vida cotidiana, o que, segundo Bomfim (a partir de sua leitura de Darwin), se traduz como um extinto de preservação.

Para Bomfim, o passado não retém o presente, mas o comprime, o pressiona a partir de possibilidades e processos. Não valorizar as experiências do passado poderia abrir margem para a degradação das potencialidades sociais, já que reduziria as perspectivas de ação conjunta entre os sujeitos, tornando-se alienados a respeito das possibilidades dos/nos processos históricos, fazendo mau uso das potencialidades históricas. A constituição de tradições a partir de narrativas históricas (especialmente as produzidas por historiadores) podem potencializar o agir, ou melhor, tratam-se de um "estímulo no sentido do plano geral de ação, ou no desenvolvimento de pensamento" (Bomfim, 1930, p. 29).

Devido ao aspecto espacial, diretamente associado à necessidade de estimular $e$ potencializar o agir a partir das experiências passadas, as histórias gerais e universais acabam por se constituir como um esforço daquele que produz sua narrativa a partir de sua identidade. Ou seja, tanto a história nacional como história geral/universal, se configuram em prol do engrandecimento de uma nação, para animar aqueles com os quais o produtor da narrativa se identifica. Enfim, a narrativa da história acaba de alguma forma, a favorecer sua nação (ou outra configuração de identificação), e termina assim por desmerecer o papel das outras em uma história geral ou universal (Bomfim, 1930, p. 38-39). Isto implica que, ao menos na configuração moderna dos Estados-Nação, agredir, destituir ou alienar uma sociedade de sua história (e suas tradições) significa despontencializar sua capacidade de se manter relativamente coesa e de progredir. Para Bomfim, é este o motivo pelo qual algumas nações modernas deturpam a história de outras, em uma busca por fragilizá-las e dominá-las (Bomfim, 1930, p. 50-51). 
Portanto, para Bomfim, a escrita da história serve a vida (assim como para Nietzsche), ou melhor, deveria servir, pois isto não ocorre necessariamente. A história escrita deve ajudar na formação da tradição, de um arcabouço de experiências conjuntas no interior e entre os grupos, sendo um estímulo para a ação cotidiana, para "o político".

\section{Considerações finais - o engajamento como oposto a sistematização científica?}

A produção deste saber histórico do início do século $\mathrm{XX}$ brasileiro, se dedicou a um plano pragmático daquilo que se considerava como urgente no debate das perspectivas do presente a partir das tensões em relação ao passado. É importante apontar que esta disposição engajada da intelectualidade foi interpretada com certa negatividade por grande parte do saber produzido nas universidades desde o final da primeira metade do século XX. Muitas destas críticas, fundadas a partir de outros padrões científicos institucionalizados, entendiam de forma anacrônica e teleológica os trabalhos destes autores como nada científicos, pessoalizados, carentes de teoria e metodologia, imprecisos e pouco especializados. Segundo Angela de Castro Gomes, algum tempo após a formação das universidades, da especialização do conhecimento científico e especialmente após o início dos governos de Vargas, gradativamente sedimentou-se uma compreensão a respeito da Primeira República (e do saber ali realizado), como "velha" e inadequada, em oposição ao Estado Novo.

Esta interpretação teleológica, muitas vezes entende a produção de saber anterior como resultado de escolhas políticas e intelectuais equivocadas, quando na verdade se trata, mais propriamente, de epistemologias diversas quanto a compreensão do que é história e qual é o ofício do historiador. No entanto, o saber histórico na Primeira República, entre várias possibilidades em disputa, se difere daquele que se sedimentou nas universidades, mesmo este tendo absorvido características da forma anterior de se produzir e entender o conhecimento.

Nesse contexto, se a identidade da disciplina conformava-se pela defesa de sua moderna cientificidade (ainda que isso significasse "uma outra" ideia de ciência ou de "quase ciência"), traduzida em procedimentos de pesquisa em arquivos, em erudição bibliográfica e narrativa literária cuidada, também se conformava por suas diferenciadas potencialidades políticos-pedagógicas (Gomes, 1996, p. 14). 
O Estado Novo foi um desdobramento dos movimentos que derrubaram o governo de Washington Luís em 1930, o que, para alguns, significou certo "rompimento" com algumas experiências passadas do país. Há uma parte da historiografia que compreende:

a) o Estado Novo como um bloco coeso, entendendo-o como a consagração dos ideais da Revolução de 1930; b) em decorrência, uma visão da Primeira República como um grande fracasso e equivoco político, praticamente desde seu começo, em 1889". "[...] Uma designação carregada de valores, que vai se estabelecer e se espraiar inclusive na literatura acadêmica, sendo utilizada de forma quase equivalente ou até mesmo como sinônimo de Primeira República (Gomes, 1996, p. 22-23).

É preciso matizar esta imagem da Primeira República, compreendendo-a a partir de sua própria historicidade, mantendo-se atento aos topos problemáticos acerca da ideia de atraso, da imprecisão científica, da falta de linearidade e sistematização dos gêneros de escrita, etc. Parte da literatura acerca da Primeira República a pensa como "o que não foi" ou "deveria ter sido", onde tal interpretação reducionista se da de forma dicotômica: "haveria os intelectuais 'vencedores e os vencidos'; os engajados politicamente e os 'técnicos' não engajados; os 'nacionalistas' e os 'copistas de estrangeirismos, etc." (Gomes, 1996, p. 27). Parte desta interpretação categoriza o período anterior à década de 1920, a muitas vezes chamada de belle époque brasileira, como sem valia, por não ser de fato "nacionalizada", e sim uma suposta mimese da cultura francesa. O modernismo, por sua vez, possuiria pouco mais que um valor artístico.

\begin{abstract}
A república "velha", segundo a versão dos ideólogos do pós-1930, teria se excedido na adoção da formula federativa, copiada dos EUA, o que não só comprometera definitivamente o próprio liberalismo no Brasil, como nos desviara do caminho centralizador já apontado pela monarquia. Por fim, toda a elite político-intelectual daquele período, em suas várias correntes, teria falhado no campo simbólico, pois não conseguiria construir nem um imaginário republicano poderoso nem um sentimento cívico de amor à nova pátria (Gomes, 1996, p. 27).
\end{abstract}

No entanto, segundo Gomes, no final do século XX e início do XXI surgiu uma nova compreensão em relação à Primeira República e o trabalho destes letrados. Nesta concepção, o conhecimento histórico produzido durante a Primeira República é percebido como uma variedade epistemológica particular à sua temporalidade. As obras destes autores são, então, muitas vezes entendidas como caracterizadas por uma pragmática engajada, mas também escolhas teórico-metodológicas específicas de sujeitos em seu tempo e espaço. As perspectivas dos trabalhos destes intelectuais não eram realizadas a partir de uma posição ingênua $e$ simplesmente arbitrária, mas constantemente estabelecidas através de densos debates teóricos e 
epistemológicos em relação a questões importantes, mesmo que, muitas vezes, a partir das dicotomias modernas a respeito da objetividade/subjetividade, parcialidade/imparcialidade, ciência/ficção.

[...] o ponto fundamental que eles [novos estudos] procuram defender é o da politização existente no campo intelectual e o comprometimento de muitos de seus integrantes com distintos projetos que, mesmo criticando o regime republicano, propunham possibilidades de ação/renovação da República. Para tanto, esses intelectuais se engajam em diversificadas estratégias de ação $e$ intervenção social, e mobilizam, para sustentá-las, os valores da moderna ciência e os instrumentos da moderna tecnologia de sua época. Esse, portanto, foi um tempo em que o investimento no debate intelectual/científico estava na ordem do dia, o que envolvia tanto as ciências naturais como as ciências sociais, entre as quais estava a História (Gomes, 1996, p. 29).

A produção de conhecimento do início do século XX está associada a busca por dissertar a respeito de uma infinidade de temas considerados urgentes para a reflexão da realidade de seus contemporâneos. É, portanto, parte de uma determinada historicidade onde texto e contexto se encontram imbricados, simultaneamente fundamentados $e$ fundamentando as possibilidades de sua realidade histórica. No interior deste panorama, o engajamento com a política, e mais ainda com o político (com as perspectivas de ação do plano da vida entre os mais diversos sujeitos, dos mais diversos cotidianos sociais) era parte fundamental e legítima de uma produção de saber comprometida com as adversidades dos matizes do real.

\section{Referências}

AGUIAR, Ronaldo Conde. O Rebelde Esquecido: tempo vida e obra de Manoel Bomfim. Rio de Janeiro: Topbooks, 2000.

BOMFIM, Manoel. O Brasil na História: deturpação das tradições, degradação política. Rio de Janeiro: Francisco Alves, 1930.

DE LUCA, Tania Regina. Leituras, projetos e (Re)vista(s) do Brasil (1916-1944). São Paulo: Editora UNESP, 2011.

DUTRA, Eliana de Freitas. Rebeldes literários da República: história e identidade nacional no Almanaque Brasileiro Garnier (1903 - 1914). Belo Horizonte: Editora UFMG, 2005.

GAIO, Henrique Pinheiro Costa. Pessimismo e Ruina: um retrato essencial do Brasil. Dissertação de mestrado defendida pela PUC-Rio em 2008. 
GOMES, Ângela de Castro. A república, a história e o IHGB. Belo Horizonte: Fino Traço, 2009.

GOMES, Ângela de Castro. História e Historiadores. Rio de Janeiro: Editora Fundação Getúlio Vargas, 1996.

GONTIJO, Rebeca. O velho vaqueano: Capistrano de Abreu (1853-1927) - memória, historiografia e escrita de si. Rio de Janeiro: 7 Letras, 2013.

GUMBRECHT, Hans Ulrich. Produção de presença; o que o sentido não consegue transmitir. Rio de Janeiro: Contraponto: Ed. PUC-RIO, 2010.

HABERMAS, Jürgen. Mudança estrutural da esfera pública: investigações quanto a uma categoria da sociedade burguesa. Rio de Janeiro: Tempo Brasileiro, 1984.

HANSEN, Patrícia Santos. Feiçôes e Fisionomia: a história do Brasil de João Ribeiro. Rio de Janeiro: Access, 2000.

NICOLAZZI, Fernando. Um estilo de história: A viagem, a memória, o ensaio. Tese de doutoramento defendida pela UFRGS em 2008.

LEAL, Maria das Graças de Andrade. Manuel Querino: entre letras e lutas; Bahia: 1851-1923. São Paulo: Annablume, 2009.

PALTI, Elías. El tiempo de la politica: El siglo XIX reconsiderado. Buenos Aires: Siglo XXI, 2007.

QUERINO, Manuel. O colono preto como fator da civilização brasileira. Jundiaí: Cadernos do mundo inteiro, 2017.

RAMOS, Julio. Desencuentros de la modernidad en América Latina. Caracas: Fundación Editorial El perro y la rana, 2009.

ROSANVALLON, Pierre. Por uma história do politico. São Paulo: Alameda, 2010.

SEVCENKO, Nicolau. Literatura como missão: tensões sociais e criação cultural na primeira república. São Paulo: Brasiliense, 1999.

SOARES, Gabriela Pellegrino. História das Ideias e mediações culturais: breves apontamentos. In: JUNQUEIRA, Mary Anne; FRANCO, Stella Maris Scatena (Orgs.). Cadernos de Seminários de Pesquisa. São 
Paulo: Departamento de História da Faculdade de Filosofia, Letras e Ciências Humanas. Universidade de São Paulo / Humanitas, 2011.

WELS, Erica Schlude. A salvação pela escrita: algumas páginas sobre a importância da literatura na constituição do sujeito e do cidadão crítico. Diadorim, Rio de Janeiro, Revista 18 volume 1, p. 116-123, Jan-Jun 2016.

${ }^{1}$ Esta ressignificação (entendida como uma deturpação por entendimentos eurocêntricos) e a não institucionalização da literatura não poderia ser entendida como um "[...] cambio por un impulso crítico de la "verdad" y la disciplina?". Ou seja, o processo de ressignificação e circularidades de ideias na América Latina não poderia ser compreendido como uma crítica as percepções europeias em torno do conceito de "verdade", de uma compreensão racional única que da acesso ou desvela o verdadeiro saber? Mais ainda, em alguns casos não poderia ser entendido como um posicionamento crítico frente a uma institucionalização ou disciplinarização do saber? (Ramos, 2009, p. 167-168).

${ }^{2}$ Segundo Dutra, conceito concebido por Herder, Michelet, Renan e Fustel de Coulanges no século XIX e de grande importância para os letrados republicanos do final do século XIX e início do século XX (Dutra, 2005, p. 83).

${ }^{3}$ Nomes importantes neste momento segundo Sevcenko: Tobias Barreto, Silvio Romero, Clóvis Bevilacqua, Arthur Orlando, Araripe Junior, Capistrano de Abreu e Graça Aranha. Aluísio Azevedo, Joaquim Nabuco, Rui Barbosa, Euclides da Cunha. Alfredo de Carvalho (historiador), José Veríssimo, Alberto Torres, Augusto dos Anjos, Cruz e Souza. Farias Brito, Coelho Neto, Bernardino Lopes. Olegário Mariano (Sevcenko, 1999, p. 78-79).

${ }^{4}$ Nossa intenção não é tratar especificamente dos almanaques, mas é importante apontar que eles também podem ser compreendidos como âmbitos de pragmática lógico-formal e estética, os quais foram fundamentais à própria formação do público leitor. Tais periódicos tornaram possíveis a publicação e recepção de livros que debatessem de forma mais detida temáticas sócio-históricas, como os ensaios os quais nos referimos. Muitos dos autores destes ensaios circulam entre espaços literários como os almanaques para participarem disto que seria a tônica deste tempo - a pragmática quer lógico-formal quer estética. Estes almanaques estão ligados a projetos de civilização e progresso, grandes divulgadores sociais e culturais, "relacionados a um processo de construção e validação de todo um código de condutas e valores que foram historicamente enraizados nas sociedades ocidentais". Ainda é preciso dizer que a rapidez e utilidade das temáticas nos almanaques não impediram as temáticas eruditas e especializadas: via-se como um espaço para combinar temas populares e eruditos - era o lugar da prática da polissemia e da literatura de massificação (Dutra, 2005, p. 35-36).

${ }^{5} \mathrm{O}$ artigo mencionado por Dutra é de autor anônimo (Dutra, 2005, p. 180-181).

${ }^{6}$ Para estas questões são de grande importância os trabalhos de Dutra (2005) sobre o Almanaque Brasileiro Garnier, Gomes (2009) sobre o IHGB e os historiadores na Primeira República, Hansen (2000) sobre a obra de João Ribeiro, De Luca (2011) sobre a Revista do Brasil, Nicolazzi (2011) sobre Gilberto Freyre, Gaio sobre Paulo Prado (2008), Gontijo (2013) sobre o trabalho de Capistrano de Abreu, Sevcenko (1989) a respeito da obra de Euclides da Cunha e Lima Barreto, entre tantos outros.

${ }^{7} \mathrm{O}$ que não deve ser entendido como uma característica negativa, pouco especializada, mas um modo diferente de operar.

${ }^{8}$ Com lógico-formais e estéticos, nos referimos ao que Gumbrecht compreende como "cultura de sentido" e "cultura de presença". A primeira, intensificada a exaustão no interior da experiência moderna, diz respeito à preocupação em concatenar de forma racionalista as compreensões sobre os diversos aspectos da realidade, focando-se principalmente na consciência humana e sua capacidade de transformar coisas em objetos. Já a "presença", muitas vezes considerada equivocadamente como menos importante, se encontra relacionada a materialidade do real, das coisas que rodeiam o corpo humano e são tangíveis a ele, da experiência afetiva e sensorial. A possibilidade de escrita da história a qual me refiro aqui, possui elementos destas duas interações com o a realidade (Gumbrecht, 2010, p. 13-14).

9 Segundo Cyril Lynch, em seu prefácio ao livro "Por uma história do político" de Pierre Rosanvallon, a história política perdeu gradativamente seu prestígio (recuperado na segunda metade do século XX) devido a acusações realizadas por críticos adeptos do materialismo histórico de realizar apologia das elites e não "ostentar padrões de cientificidade" ao mesmo tempo que "conferia importância demasiada aos humores dos dirigentes políticos". (Rosanvallon, 2010, p. 11-12).

${ }^{10}$ Tal possibilidade se encontra em outros gêneros de escrita, tais quais livros, almanaques, discursos, trabalhos didáticos, revistas, jornais e outros produtos culturais impressos.

${ }^{11}$ Para saber mais sobre a biografia de Bomfim: (Aguiar, 2000).

${ }^{12}$ Para saber mais sobre a biografia de Querino: (Leal, 2009).

${ }^{13}$ Saliento que este investimento moderno em torno do projeto "universalista" de "progresso" e "civilização" do Estado-Nação é profundamente violento, produzindo incontáveis epstemicídios e etnocídios a partir dos processos de colonização, escravidão, entre outros. Acrescento ainda que, mesmo que procuro evidenciar as potencialidades em muitos dos textos a respeito da temática histórica do final do século XIX e início do século XX, devemos lembrar que em muitos deles podemos encontrar a intensificação de perspectivas racialistas (como nos trabalhos de Oliveira Viana e Silvio Romero). Ainda que esta possibilidade fosse parte daquela historicidade, muitos outros autores a criticaram e 
tencionaram no interior de compreensões que priorizavam os elementos humanos culturais (como Manuel Querino, Theodoro Sampaio e Manoel Bomfim).

${ }^{14}$ A Kulturgeschiche trata-se da vertente da história cultural alemã na segunda metade do século XIX (tendo como expoentes Burckhardt, Freytag e Riehl). Tal perspectiva culturalista se opunha a história política "a partir das reivindicações de autonomia metodológica e de supremacia". Segundo Hansen, uma importante chave de leitura pra a compreensão do livro História do Brasil de João Ribeiro e, creio, de outros autores da mesma temporalidade. (Hansen, 2000, p. 73-74).

${ }^{15}$ É importante apontar que este argumento se encontra na obra de Querino muito antes da de Gilberto Freyre. 